\title{
In Re: Experimental Education
}

\author{
William Brooks
}

\section{Arrival}

This chapter is borne to the harbour of my being on three currents. The first, a series of gentle swells on the phrase "in re", is manifested thus far in one published article, a second in press, and a third in preparation [5-7]. The second is a more enduring stream of thought deriving from the writings of William James and John Dewey. And the third, with which I shall begin, is a pool that formed and flowed from California in 2012.

\section{The Stanford Symposium}

In February of 2012 Stanford University hosted a symposium devoted to the teaching of composition at the doctoral level in the United States. Nine distinguished teachers from major institutions critiqued student works, joined in round-table discussions, and presented papers setting forth their own perspectives and philosophies. The latter, together with an overview of the entire event, were published in Contemporary Music Review [11, pp. 249-329].

\section{Talent and Skill}

Erik Ulman [34] prefaced the papers themselves with a summary that stressed the diversity represented in pedagogy and curriculum. But in fact all the participants appeared to agree on at least one key point: the practice and therefore the teaching of

\footnotetext{
W. Brooks ( $\square)$

University of York, Heslington, York, UK

e-mail:w.f.brooks@york.ac.uk 
composition includes (or has been thought to include) two quite distinct components. Mark Applebaum [1], the instigator of the symposium, put it thus: "Can talent be taught? I suspect not. ... We can, however, teach skills" (p. 262). Fred Lerdahl [24] offered a similar assessment: "Instruction in music composition divides roughly into two parts: teaching craftsmanship and guiding a student toward his or her own path. The first can be taught, but the second is a mysterious undertaking" (p. 291). Shulamit Ran [27] argued that "an ideal composition teacher, at any level, is (1) able to help the student listen, critically, and in a deep way, to his/her own music, and (2) considers it a priority to develop and refine the kind of technical tools that will help the student implement his/her personal artistic vision" (p. 307). And Roger Reynolds' [29] more general description rested on a similar dualism: "I feel it is essential for every creative musician to develop what I will call—in a general sense — a 'way'. This is not simply a matter of compositional techniques, characteristic ways of handling pitch, temporal, and timbric resource, for example. It also implies a path from initial impulse to final product; a path that allows a composer to be confident that $\mathrm{s} / \mathrm{he}$ can proceed with moderate certainty under any circumstances, whatever the resources available, whatever the nature of the desired musical end" (p. 319).

Others approached this duality from a more personal perspective that called clean distinctions into question. Martin Bresnick [2] discussed the difference as embodied in his two principal teachers: John Chowning, who directed him to the technical dimensions of sound itself, and György Ligeti, who demanded originality to the extent of asking for the impossible. The implication was that Bresnick's own compositional self was born only from the integration of these two components. Scott Lindroth [25] also drew on examples from his own studies; he recalled an "inscrutable" teacher and opposed this with one who offered "advice on details of orchestration, counterpoint, texture, proportions, and the like" (p. 298). He argued that advanced students benefit most from a third approach, in which a teacher seeks to cause them to, in effect, lose their ways, their habits. Chaya Czernowin [13] went much further, arguing that all such pedagogical manoeuvres are beside the point, because "every separation between means or technique on one hand and expression or concept or idea on the other is totally false" (p. 285).

\section{History and Diversity}

A second recurring issue concerned the place of historical precedent: to what extent, if any, ought students be knowledgeable about existing musics, and what should these be? On such questions there was a clear division of opinion, which Ullman [34] summarised thus: "While some in various ways maintained that the Western musical tradition could or should retain its privileged curricular status, others wanted to identify a core less with this or any other body of work and practices and more with abstract principles assumed to be more fundamental or desirable" (p. 263). Ran [27] was the most uncompromisingly and unrepentantly conservative: "In a deep sense, Bach and Beethoven, Schubert and Brahms, and so many other great composers 
whose music has withstood the test of time, were my greatest teachers. (As were Stravinsky, Bartok, Schoenberg, Berg, Varèse, the list only begins.) I believe this is so not because this music forms an important tradition, though of course it does, but because it is GREAT MUSIC. Call me old-fashioned, but I continue to consider this kind of training — engaging with great music in any way possible —invaluable" (p. 306). Applebaum [1] was perhaps the most sceptical: "Maslow's 'law of the instrument' warns us that poverty of imagination is the consequence of a narrow palette: If all you have is a hammer, every problem looks like a nail. . . Still hanging about like a miasma is the perpetually re-inherited idea that literacy in Western art music and the ability to do tonal harmony are necessary. ... I remain queasy about the notion that just because I had to learn how to use a hammer, so should you" (pp. 262-263). Edmund J. Campion [9] cast the historical net more widely with a question that approached belligerence: "[Are you] going to compose inside today's accepted modes of musical expression or are you going to create by exploring and researching emerging music practices?" (p. 280).

Applebaum's and Campion's critiques rested on the observation that today's environment is characterised by a diversity of styles and experiences; students bring other tools than "hammers" to their studies. Lerdahl [24] concurred, but he drew the opposite conclusion: "I firmly believe in traditional instruction in ear training, tonal harmony and counterpoint, tonal analysis and standard instrumentation and orchestration. Such instruction is important for two reasons. First, one learns from the central tradition. ... Second, contemporary music has not coalesced into a common practice in which basic principles of musical organization are agreed upon. Instead, there are many styles and compositional methods, and each composer must find his or her way through the maze" (p. 292). Lindroth [25], too, advocated conventional training, but primarily "for the inexperienced composer" (p. 299). And Czernowin [13] again pushed the argument much further, looking beyond "practices" and "styles" to focus on "authenticity": "We have endless numbers of common practices, to such a degree that we have actually no common practice at all. ... Thus, the main problem today is not how to become very good at one or more of these styles, working within a style. It is also not the act of choosing a style or a combination of styles. Today ... the main problem has to do with the question of authenticity" (p. 284).

\section{Inner and Outer}

These two issues would seem to arise from a single source, a sense that composition partakes of two worlds: the internal (talent, an authentic "voice") and the external (technique, historical understanding). The relationship between the internal and the external, in several composers' minds, would seem to be a circular one-an imprecise and fluctuating loop, a kind of feedback, in which internal impulses produce external actions and external stimuli produce internal responses. Czernowin and Bresnick both implied such a process, but Reynolds [29] presented it explicitly: "Composition is an undertaking of cyclical character: from an initial decision or urging toward a creative 
act; through the mulling over of resources, scale, form, media, and so on; through the writing out of a score of some sort; then interaction with performers and performance spaces in rehearsal; the performance itself, and finally the reconsideration over time of how the performance 'felt' in relation to what one intended. ... Every stage in the cycle matters, but what matters most is that one engages with the process in a committed and individual manner. ... And the more such cycles a student goes through attentively, and, ideally, interactively with a thoughtful observer-a mentor-at hand, the faster one's craft, one's 'voice', emerges and refines itself"' (p. 316).

One thinks of Charles Ives [19], ranting about inner "music" going out and outer "sound" coming in: "My God! What has sound got to do with music! ... Why can't music go out in the same way it comes in to a man, without having to crawl over a fence of sounds, thoraxes, catguts, wood, wire, and brass?" (p. 84). Or, in a more moderate moment, attempting to steer a middle course between conformity and rebellion: "Why tonality as such should be thrown out for good I can't see. Why it should always be present I can't see. It depends . . . on what one is trying to do, and on the state of the mind, the time of day or other accidents of life" [20, p. 117].

Martin Bresnick [2], discussing the place of history in composition, attempted a similar middle course: "The repertoire of Western music [is] taught by music theorists and musicologists... It seems to me crucial that this valuable historical repository be reclaimed by composers for their own creative purposes" (p. 272). And from this one gets not to Ives but to John Cage, speaking to Richard Kostelanetz in 1968: "We must get ourselves into a situation where we can use our experience no matter what it is. We must take intentional material, like Beethoven, and turn it to non-intention" [23, p. 58].

Cage and Ives; the exteriority of sound; the interiority of music; the cycle that flows first outward, then inward; the reconstruction of history by and into an authentic self; the very concept of music as useful experience-all these suggest that these currents of thought draw on the wellspring of American pragmatism, especially on the writings of John Dewey and William James. Bresnick [2] links himself explicitly to such forbears: "This empirical, pragmatic approach is, I think, largely an American attitude, whose origins may be found in Emerson, Whitman, William James, John Dewey, and many others. ... John Chowning discreetly and transparently taught me his way of working-by the vivid example of his excitement in discovering new sounds, his new ways of sounding them, and by his openness to thoughtful experiment. The value of these efforts was not always immediately apparent: things failed, or proved, in practice, to be ineffectual or unnecessary. . . . I remain convinced by this sort of 'materialist,' empirical approach to composition" (p. 271).

Bresnick's leap is not surprising. Most of the composers at Stanford were Americans, after all, and many situated their work in relation to (if not as part of) so-called "experimental" music. But they spoke of this only indirectly; the focus of the symposium was their educational approach and philosophy. "Experiment", "empirical", "experience", "education"- these are key terms in writings by the pragmatists, and they played an important part in the Stanford discussions. And pragmatists-Dewey, especially - were deeply concerned with how experience is 
made into knowledge, or art, and how knowledge or art is embedded in experience. That is a prime educational preoccupation, and Dewey exercised a profound influence in America on what became known as "progressive" education, in which attention to individuality, "authenticity", plays a central role. It seems almost inevitable, really, that a gathering of eminent American teachers of creative practice (composition) would invoke, often indirectly, the progressive thinking that flowed through much of American culture during the previous century; and it thus seems quite reasonable that probing their discourse for underlying issues leads to a terrain where Dewey, James, and the pragmatic tradition of thought are plausible guides.

But what, exactly, are the points of contact? Where are the resonances, and what the struck sound? And what can this have to do with POINT-temporally and geographically distant and in no way conceived as an educational project?

\section{Pragmatism}

There is certainly historical evidence for a link between pragmatism and experimental music. The link between Cage and Dewey was explored by Joan Retallack, writing in 1992. "Cage's work ... unfolds within the American pragmatist tradition characterized by the aesthetic theory of the philosopher John Dewey", she writes [28, p. 243], and Dewey reappears regularly in the analysis of Cage's "poethics" that follows. In a later essay, Austin Clarkson [10] explored the relationship between Cage's "oriental" aesthetic and William James, mediated by Jung and Suzuki. I myself have touched on this topic [3, 4], and Edward Crooks's superb dissertation [12] explores some of the hidden Western sources in Cage's "oriental" influences.

For Ives there is a surprising gap-possibly because he himself is so resolutely focused on Emerson that other philosophers have gotten short shrift. But four decades ago Rosalie Sandra Perry [26] tied Ives to James and pragmatism in a seminal chapter; and more recently Christopher Bruhn's fine dissertation [8] has picked up and extended the threads. Suffice it to say that there is ample reason to stipulate kinship, if only because both Ives and James trace their lineage to Emerson.

In what follows I will leave such historical matters untouched. I propose rather to discuss the four key terms noted above-experiment, empiricism, experience, and education-with particular reference to James and Dewey, secondary links to the Stanford conversations and, eventually, a return to the POINT project.

\section{Experiment}

I first encountered Gerhard Nierhaus and the POINT project at the Orpheus Institute in Ghent, Belgium. The Orpheus Research Centre, at which I have been a senior research fellow since 2009, has fostered an extensive examination of the term "experiment" in recent years, particularly as applied to artistic research in music. The scientistphilosopher Hans-Jörg Rheinberger provided one model for exploration [31]; I have 
approached the problem with reference to experimental music [5]; and recently Katharine Coessens brought Friedrich Steinle to initiate a discussion of "exploratory experimentation", based in part on Goethe's experimental work with colour [30, 32]. It is no wonder, then, that in drafting the present chapter my thought has drifted to these three ongoing Orpheus conversations and the implications they might have for POINT. All three approaches can be mapped crudely but convincingly onto oppositions between inner and outer that somewhat resemble the dualism that underlay the Stanford symposium. Rheinberger distinguishes, crucially, between "experiment" and "experimental system"; the latter-the constellation within which the former is manifested-embraces laboratory, social relations, economic factors, and uncounted other forces. The "experiment"-historically a self-contained idea that arises from the mind, from "pure" thought, and is then tested in a "material" world-thereby becomes a much messier thing. The "system" in which it is embedded feeds into the construction of the "idea"; thought ceases to be "pure", and the "material" is constantly reconfigured in a series of cycles inwards, outwards, and around the putative "scientist". The attractiveness of this model to researchers in artistic practice is evident.

Similarly, in my analysis of "experimental music", I found it useful to distinguish between "test" and "observation". The former, I argued, is associated with judgment and value; a test determines the validity of a concept or hypothesis that is formed, in effect, in the mind prior to the experiment. "Observation", on the other hand, entails activities undertaken with relatively few preconceptions, and hypotheses (if any) are formed only after the experiment has occurred. Tests are responses to questions of the form "Is it the case that . . .?"; observations arise from "What happens if ...?" Test and observation are two halves of a cycle that (anticipating Dewey) we might call experience: the test points outward, from self to world, while observation feeds the self from the world.

This is very like the distinction that Steinle and others have drawn between "theory-driven" and "exploratory" experimentation. An experiment driven by theory is determined entirely by a set of predicted outcomes; anything that does not bear on the prediction is ignored. Newton, Steinle argues [30], worked in this manner in evolving his theory of optics: each confirmed prediction gave rise to a new hypothesis to be subjected to experiment (and thus confirmed); if a prediction was disproved, it was the theory (not the experimental experience) that was subjected to examination. "Exploratory" experiment, on the other hand, as practiced by Goethe and others, freely accumulates data within a bounded universe, a "topic"; only after (or in the course of) this open, observational praxis are relationships and consequences inferred.

In all three models, then, there is a rough and slippery distinction between inner and outer actions and the orders in which they are undertaken. Without plunging into the abyss of metaphysics, it is useful to speak of mind and world, idea and reality. To the extent that pragmatism was a response to the non-negotiable conflict between "idealism" and "realism", it effectively sidestepped the import of this distinction without denying it: mind and world, idea and reality form a cycle, a closed system 
of mutual effects that are apprehended through actions and their consequencespractical actions: pragmatism.

\section{Empiricism}

Today three philosophers are accepted as the patriarchs of pragmatism: Charles Saunders Peirce, William James, and John Dewey. All three embraced a form of empiricism in which our inner world of judgment, thought, and intelligence is contingent upon an outer world — an apprehended reality. But the contingent process was not simple observation; the mind does not stand above, apart from the outer world, determining properties and rules by applying an innate (inner) logic. The mind is part of the world, and part of the body, and part of the act of sensation; the world is apprehended by action and by consequence: an entity is what it is because someone does things to it (or in it) and observes the result. This is a kind of exploratory experimentation, with principles arising from a variety of acts undertaken not quite at hazard. Other than temporal continuity, spatial proximity, and the biological laws of sensation (the "principles of psychology", one might say [21]) there is no need to assume a priori properties.

Peirce, James, and Dewey differed in important respects. Peirce came to call his thinking "pragmaticist"; James embraced "pragmatism", having taken the term from Peirce originally; Dewey preferred "instrumentalism". For Peirce the essential problem was meaning; for James, arguably, it was truth; and for Dewey it was learning (or, in the present context, creativity). Peirce was led inevitably to the construction of a semiology; James was required to confront belief; and Dewey devoted himself to society, education, and art. But the thought of all three was radical, as James applied the term: all three argued that the subject of the inquiry could not be separated from the inquiry itself. The meaning of "meaning" must be explicated using the properties that "meaning" has come to acquire. An explanation of creativity has to account for the creation of the explication. And even empiricism, James argues, must be radical: "the parts of experience hold together from next to next by relations that are themselves parts of experience" [22, p. xiii].

"Radical", too, are the constructions of "experiment" presented above. Rheinberger's "experimental system" must include the prevailing models for experimentation that underpin the laboratory work. But the "experimental system" is itself one such model; thus it enters the world it is describing and hence must account for its own being. Similarly, what Steinle calls "exploratory experiment" (and what I have called "observation") arises only out of its own practice. Tests, which are "theorydriven", arise from principles that are assumed to exist in a different realm from the objects being manipulated: the law of gravity has no effect on the motions of the planets. Exploratory experimentation, in contrast, is intrinsically vague and amorphous, itself being constantly reshaped in response to what is observed; the construction of an exploratory experiment — of the term itself — is itself an exploratory experiment. Experimental systems and exploratory experiments are inextricably entangled 
in the shifting relations of the self with the world around it, and those relations are themselves part of the system constructed, the domain explored-in a word, part of experience.

\section{Experience}

And so we come to "experience", and - in this context—especially to John Dewey's summative work, Art as Experience [16]. In this Dewey applies the principles of radical empiricism to artistic expression and esthetic (Dewey's spelling) understanding. Consistent with the pragmatic method, he begins by refusing a priori distinctionsin particular, the distinction between "fine" art and daily life. As an illustration, he observes that "the intelligent mechanic, engaged in his job, interested in doing well and finding satisfaction in his handiwork, caring for his materials and tools with genuine affection, is artistically engaged" (p. 5). It follows that art resides not in objects-paintings, buildings, sounds—but in experiences: "Even a crude experience, if authentically an experience, is more fit to give a clue to the intrinsic nature of esthetic experience than is an object already set apart from any other mode of experience" (p. 11).

The first problem, then, is to examine experience. Again Dewey starts from a tabula rasa: the only assumption is that experience is necessary to life, and "life goes on in an environment; not merely in it but because of it, through interaction with it" (p. 13). In that sense experience is continuous and indivisible. But we speak of having an experience-something that is bounded and extracted from the continuity. What creates the boundaries? The pragmatic answer is that we do, by the way in which we direct our attention, the actions we take. We judge something complete, and we attend to something else, something "new". Recall James: relations between "parts of experience" are themselves part of experience; and a relation called "completion" arises, becomes part of experience, when we feel we have begun something different. "We have an experience", Dewey writes, "when the material experienced runs its course to fulfillment" (p. 35). We ascribe to an experience a unity, a distinguishing quality or qualities that sets it apart from others; and when that unity or quality changes fundamentally, we declare the experience complete. An experience need not be continuous - cooking a meal might be interrupted by a phone call, or reading a novel halted for days or weeks - but in naming or characterising the experience, such interruptions are disregarded: it is the unifying quality that binds the experience together, not temporal continuity.

But within an experience, "every successive part flows freely, without seam and without unfilled blanks, into what ensues" (p. 36). In that sense an experience is just a part of life; an experience results from "interaction between a live creature and some aspect of the world in which he lives" (p. 44). The interaction proceeds cyclically, in an alternation of states that Dewey characterises as "doing" and "undergoing"; and from this arises the flow, the unity of an experience. "A man does something; he lifts, let us say, a stone. In consequence he undergoes, suffers, something: the 
weight, strain, texture of the surface of the thing lifted" (ibid., my italics). The experience consists not merely in the sequence of events but in the binding unity formed by the relationship between them: "An experience ... is not just doing and undergoing in alternation, but consists of them in relationship" (ibid.) (Recall James, again).

But since Dewey situates art not in objects but in experience, it follows that "art ... unites the very same relation of doing and undergoing, outgoing and incoming energy, that makes an experience to be an experience" (p. 48). Some experiences, however, have qualities that we designate as "esthetic", and Dewey distinguishes these from others that are "dominantly intellectual or practical" (p. 55). In the latter sort of experience, an end is attained; from the start, the goal is to bring the experience to a useful conclusion, and the experience has no value other than as a means to the end. The experience, we might say, is "theory-driven"; it has no "exploratory" properties, and it includes nothing that has not been anticipated. In an "esthetic" experience, in contrast, doing and undergoing stand in a relationship that is itself of value; the artist and the percipient come to explore a process, not to attain an end. Our interaction with the world, Dewey summarises, "is peculiarly and dominantly esthetic... when the factors that determine anything which can be called an experience are lifted high above the threshold of perception and are made manifest for their own sake" (p. 57). Thus an esthetic experience or artistic product is only incidentally about an image, a theme, or a character; at its heart it is about experience itself. Hence the value of esthetic experience does not lie in tangible accomplishments, though these may arise in the course of the experience. We may do something new or make a new object; we may learn something about a place, about a person, about form, harmony, design; but above all we learn above all how to experience things esthetically. All experience is recursive in some sense; an experience becomes a part of future experience; so for a pragmatist, we might say, esthetic experience is radically esthetic.

\section{Education}

Having been led to learning through art, we are invited into the domain with which Dewey is perhaps most widely associated: educational theory. Dewey's engagement with education persisted throughout his career, beginning with his early, exploratory experiments at the "laboratory school" at the University of Chicago. These culminated in Democracy and Education [14], which became a touchstone for "progressive" education in the United States. But Dewey revisited the topic intermittently for the rest of his life, and he wrote a key summary in 1938, just four years after Art as Experience. In this-Experience and Education-he critiqued the schism between "traditional" and "progressive" education and implicitly linked education with art by means of the term his titles had in common: experience.

Experience and Education is less formal than the earlier volumes, and Dewey assumes an understanding of some concepts that he had previously explained at 
length. Experience is, as before, an interaction of an organism with its environment; and, as before, interaction includes the two aspects that Dewey called "doing" and "undergoing" in Art as Experience. But Dewey's concern is now less with the boundaries of an experience and more with the continuity formed by experience as a whole. It is in this continuity that the basis for a critique of education is found, for "every experience both takes up something from those which have gone before and modifies in some way the qualities of those which come after" [17, p. 27]. People learn from experience, and learning is therefore continuous; the question, for Dewey (as for the composition teachers at Stanford), is how to distinguish an educational experience from the learning that happens, willy-nilly, all the time.

Growth-development-also happens continuously, and in some ways would seem to be equivalent to education. But, Dewey observes, some growth enhances future growth, and some hinders it; if the hindrance is too great, the organism withers and eventually dies. Hence, the key question is: "Does [a] particular form of growth create conditions for further growth, or does it set up conditions that shut off the person... from the occasions, stimuli, and opportunities for continuing growth in new directions?" (p. 29). Dewey's answer is unequivocal: "When and only when development in a particular line conduces to continuing growth does it answer to the criterion of education" (ibid.; italics original).

This is a radical education closely allied to radical empiricism and radical esthetics. In all three domains attention is focused not on objects but relations, not on ends but on processes. These processes are cyclic: experiences-the common basis for all three enquiries - are evaluated by whether they include, enhance, advance future experiences. When they do not-when experience is divorced from the environment and situated solely within the self-empiricism becomes idealism, esthetics become formalism, education becomes training. "The most important attitude that can be formed", Dewey writes, "is that of desire to go on learning" (p. 49).

Not all education, not all experience, is radical in this sense. We live much of our lives by habit, a topic that Dewey [15] and James [21, v. 1 Chap. 4] both treated at length. Habits are necessary and beneficial; they are acquired through experience and they may result in art. But they are not radically esthetic or educational, except insofar as one can speak of acquiring a habit of inquiry or a habit of esthetic engagement. Workaday habits—walking, talking, eating, grooming, resting — do not hinder an organism's growth, but neither do they further it; they merely maintain it. They are beneficial, but they are not educative.

There are, however, experiences that are not beneficial-experiences that are miseducational or counter-esthetic. Dewey gives several examples in both domains, and they are remarkably similar. From Experience and Education [17]: "A [miseducative] experience may be such as to engender callousness; it may produce lack of sensitivity and of responsiveness. Then the possibilities of having richer experience in the future are restricted... [It] may increase a person's automatic skill in a particular direction and yet tend to land him in a groove or rut; ... [it] may be immediately enjoyable and yet promote the formation of a slack and careless attitude [that modifies] the quality of subsequent experiences so as to prevent a person from getting out of them what they have to give" (pp. 13-14). And from Art as Experience [16]: 
"The enemies of the esthetic are neither the practical nor the intellectual. They are the humdrum; slackness of loose ends; submission to convention in practice and intellectual procedure. Rigid abstinence, coerced submission, tightness on one side and dissipation, incoherence and aimless indulgence on the other, are deviations in opposite directions from the unity of an experience" (p. 40).

\section{Stanford Revisited}

With rhetoric like this we are led back to the discussion at the Stanford symposium. The problem there- - how to teach composition-integrates both of Dewey's concerns, the esthetic and the educational. And certain of Dewey's insights illuminate the points of contention at Stanford. Recall that Dewey rejected an a priori distinction between "fine" art and what might be called the arts of life [33]; how does this affect the Stanford dichotomies between "talent" and "skill", between "art" and "craft"? If "the intelligent mechanic" is artistically engaged, can we not say the same of the intelligent composer writing, say, species counterpoint? When would we not want to say that?

For a pragmatist, all depends on the nature of the experience. If the counterpoint is an exercise and only an exercise, then the activity does not further growth and is not truly educational; if the experience does not illuminate experience itself, it is not truly esthetic. But the same might be said of a composer determined to display an original "talent", a distinct "voice": if display is the purpose, experience is not "lifted high" and the work is not esthetic. It does not matter what kind of work is undertaken; from an educational perspective, the experience is worthy if it enhances the potential for future growth, and from an esthetic perspective, the experience is worthy if elevates the understanding of experience. The two amount to very nearly the same thing: an esthetic experience is usually educational; and an educational experience, if concerned with musical composition, will, in general, be esthetic.

Much the same applies to the place of historical repertoire in teaching. Indeed, Dewey addresses exactly this point, more broadly, in Experience and Education. First he observes that when one attends to any phenomenon, the attention occurs in the present. Pragmatically speaking, then, there is no necessary difference between encountering a phenomenon that has been encountered before and one that is entirely new; the experience can be educational — or esthetic — in either case. Moreover, experience produces "a continuous spiral", Dewey written, an "inescapable linkage of the present with the past", in which an experience, when completed, becomes "the ground for further experiences" [17, p. 97]. Again, the educational value resides in the nature of the experience: if one studies Bach in order to have studied Bach (for example, to pass an examination), the experience is not educational; but if the experience of studying Bach leads forward "into an expanding world of subject-matter" (p. 111), it is. A similar argument applies to esthetic value. Shulamit Ran pleads passionately for the study of an historical repertoire "because it is GREAT MUSIC" [27, p. 306]; but the greatness resides not in the object-the "music"-but in the experience. Acquiring 
technique or knowledge from the study of "Bach" will probably not be esthetically satisfying, and the musical experience will be something other than "great"; but when the experience of Bach's music brings experience itself to the fore, greatness happens.

Finally, the underlying tension between "inner" and "outer" worlds at Stanford also appears in pragmatism, as we have seen. But to a pragmatist there is no reason to take sides; organisms and environment interpenetrate in unending cycles of doings and undergoings - music "going out" and "coming in", wrote Ives - that constitute experience, whether educational or esthetic. This is precisely the model for composition that Roger Reynolds put forth, with the additional suggestion that the educational experience is enhanced if a "thoughtful observer - a mentor-[is] at hand" [29, p. 316]. Again, however, the experience itself must be the touchstone for educational value: if the experience is such that the mentor remains needed for future work, it has restricted growth, and it is mis-educative; but if the experience enables a student to grow in new, unanticipated ways, independent of the mentor, it is profoundly educational.

In sum, it would seem that the deliberations at Stanford invoke and continue a long-standing discourse - now a century old-about "progressive" education. And because the education, in this case, concerns music, they also shed light on the interconnection between esthetics and education that Dewey implied in his two summative volumes. The teachers who gathered at Stanford are engaged in processes of exploratory experiment-in tandem, collectively, and in sequence, individually. They proceed not from an a priori theory by which to teach composition but rather from a theory - a reflective analysis - that develops from experience and that constantly evolves as one experience succeeds another. The teacher grows along with the student; both are educated. The objective is the creation not of objects with specific, approved properties but of experiences - experiences that are both esthetic and educational, experiences that enhance the qualities of future experiences and that enable growth in "an expanding world". The nature of these experiences cannot be specified in advance without severely limiting their potential; any music that results is, in that sense, and regardless of its surface features, experimental music. And the associated education, leading and following, interpenetrating cyclically with the work that is done, is experimental education.

As is, I will now claim, the POINT project.

\section{The POINT Project}

What is the POINT project, viewed through the lens of pragmatism?

In the final section of this chapter I will argue, first, that the technical roots for POINT extend deep into the bedrock of experimental music, but that POINT can be distinguished from many of its predecessors by the type of experiment it manifests. Second, I will suggest that the philosophical roots for POINT reach back to radical empiricism and that it formalises, in a sense, the pragmatic concept of experience, especially as explained by Dewey; because of this, the POINT project is linked 
with the issues raised at Stanford. Third, I will claim that POINT results in esthetic experiences - music, if you will - that arise in ways consistent with Dewey; in this, too, it serves to illuminate some points of discussion at the Stanford symposium. And finally, I will suggest that POINT is, at its foundation, a pedagogical tool, one that pertains not only to the teaching of composition but also to the agenda of progressive education, one that is of interest not only to the composers and researchers involved but to a much wider community of practitioners.

\section{POINT and Experimental Music}

In POINT, algorithms are devised and employed to make musical compositions. One can argue that the foundations of algorithmic composition are lost in history-that a canon, after all, is a kind of algorithm, and that the first notated algorithmic music is "Sumer is icumen in". But the term is more usually associated with a compositional practice that began in the 1950s and that was from the outset associated with the phrase "experimental music". That was the title of Lejaren Hiller's seminal publication [18], recounting the first attempts at computer-assisted composition, and it has persisted to the present in institutions like the University of Illinois's "experimental music studios".

As I have shown elsewhere [5], however, "experimental music" immediately came to mean two different things. On the one hand, in the work of Hiller and other practitioners like Milton Babbitt, the "experiments" conformed to classic "theorydriven" models. A hypothesis was formed and tested by means of an algorithm; this was predicted to produce results possessing specified properties, and if it failed to do so, it was rejected. On the other hand, in the work of John Cage and others, algorithms (for Cage, chance procedures) were employed precisely because their outcomes could not be predicted. The result was to be experienced esthetically regardless of its nature.

Cage's experimentation entails “observation", in opposition to Hiller's "tests"; and this, I have said, is similar to the opposition between theory-driven and exploratory experimentation. But the two are not exactly equivalent. In Cage's work, each "experiment"- each "piece", if you will—stands apart from the others; each is sufficient unto itself. There is no need to generalise; in fact, generalisations - theoriesare assumed to undermine the value, the individuality, of future experiments. In exploratory experimentation, in contrast, a series of experiments are conducted, not quite at hazard and sharing a single field of inquiry (though this may be very vaguely defined). At some point (also vaguely defined) the experimenter brings all the outcomes together to form a theory, a conception of the whole. This theory can then be (but need not be) the basis for subsequent "theory-driven" experiments.

The latter model is used in POINT. An algorithm is devised, applied, and evaluated-but not with the objective of testing or altering the algorithm (though changes may be made) but with the objective of clarifying the objective. "Oh!" the composer says, upon experiencing the outcome, "that's interesting, but I think I must have meant something different". Or, perhaps, "Oh! that's really unexpected; let's 
see where it goes". The goal to be attained at the end of the series of experiments is, at least in part, determined during the course of the experiments themselves.

From the perspective of the participating composer, the process is therefore one of exploratory experimentation. From the perspective of the researcher, the process is also exploratory, but on a larger scale. No two composers are alike; for each different algorithms are needed, and each composer's own exploratory process is distinctive. In aggregate, the composers form a collection of experiments that share a single field of enquiry - algorithmic composition of music-but do not constitute an orderly route to a pre-determined goal. What is the "theory" that unifies all the compositional acts, all the algorithms? We don't know-certainly at the beginning, and quite possibly even at the end. We can be assured only that new relations between "parts of experience" will be observed and that these will themselves be factors in the generation of future experiments.

\section{POINT and Experience}

I have just paraphrased William James's characterisation of radical empiricism. POINT is radically empirical because at every stage the relations between its "parts"-whether components of a computer program, musical outputs, or composerly responses - are taken into the experience upon which the next iteration will be based. Indeed, POINT formalises this process; one might even say that it formalises experience in the abstract. Doing and undergoing - which normally form a fluid continuity, mediated only by the senses - are split by technological intervention: the composer "does" only by means of the computer; the composer "undergoes" only in response to the computer. This split creates clear divisions in the stream of experience: there is an experience (an algorithm is devised), then there is another (an output results), then a third (the composer responds), and so forth. A certain kind of relation-beginning and ending - is elevated, within experience in general, to a dominant position; and at the boundary, the point at which one experience ends and the next begins, there occurs a change in medium: from computer code to musical score to verbal discourse, cycling forward. The participating composer is placed in a situation $[17$, p. 39] that enables self-awareness about the way experience is experienced.

The experience of the researcher embraces a much broader field of interactions, but again these are formalised in a way that creates distinct boundaries between experiences. One composer departs, another arrives: the boundary creates two different experiences. Each of these, in turn, can be parsed into distinct units, as above; the whole can be thus, in this instance, structured hierarchically. Think of a visit to an art gallery: "Les Demoiselles d'Avignon" names an experience, bounded by the frame around the painting, that is contained within an experience named "gallery 2", bounded by walls and doorways, that is contained within an experience named "the Museum of Modern Art", bounded by entering and exiting a building. But experience need not be nested in this way; we could equally think of a single, unbroken experience: the journey through the gallery—steps, stairs, pauses, turns. How we experience 
the experience is determined pragmatically, perhaps arising from the question asked: "Where did I go?" requires something quite different from "What did I see?".

Movement between these experiential poles - the discrete and the continuous (with all possible gradations between) - occurs constantly and is itself part of experience. It occupies a central place in conventional models of composition, such as those put forth at Stanford: the composer is concerned with materials, the composer is concerned with form; the work is comprised of parts, the work constitutes a whole; the music is experienced in isolation; the music is experienced in relation to other music. Self-awareness of one's behaviour, moving forwards and back along these spectra, is assumed to be beneficial, and a teacher serves in part to encourage such self-awareness. By juxtaposing a strictly hierarchical experience with an intuitive, fluid one, POINT provided participating composers with an opportunity for structured self-scrutiny, a situation in which they could work upon their method of working.

\section{POINT and the Esthetic}

POINT makes no assumptions about the nature of compositional materials. A composer starts from an image; very well, the computer will start from an image. A composer starts from a series of intervals; very well, the computer will generate such a series. Artistic creations-musical works - are not constrained by technical attributes; esthetic experience can occur in the presence of music of any type. Dewey's mechanic, "engaged in his job, interested in doing well and finding satisfaction in his handiwork", would recognise POINT as a useful and adaptable tool.

In that sense, POINT is a kind of work-desk for a composer, or a laboratory for a researcher: it constitutes an "experimental system" that includes equipment, a working method, and designated roles for participants, the whole intertwined with an environment that extends to social and economic concerns. It itself would seem to have no esthetic qualities, other than those experienced in using any well-made tool-a brush, a knife, a skillet. It is in the results that are produced - the "outputs" of the project - that the esthetic will be experienced.

But if this is all that matters for POINT, the project as a whole is simply directed towards the production of "music"; it is goal-directed-the sort of experience that Dewey characterised as "dominantly intellectual or practical". In effect, the project becomes merely a mechanism for composing music, and an obvious question arises: why bother? Composers do perfectly well on their own; what need have they for POINT? If the esthetic experience of a work created in POINT cannot be differentiated from that of a work created elsewhere, from a pragmatic perspective the experience is the same, and POINT is irrelevant.

Clearly something else is at work here; POINT is more than a work-desk, more even than an experimental system. POINT is not of value because it results in compositions that can be esthetically experienced; POINT is an esthetic experience in itself. The participating composer interacts with the experience of composing, not merely 
with an environment made up of compositional materials and other familiar entities. In an esthetic experience, Dewey requires [16, p. 57], "the factors that determine anything which can be called an experience are lifted high above the threshold of perception and are made manifest for their own sake". And that is precisely what happens in POINT. The esthetic experience forms (informs, transforms, re-forms) future esthetic experiences-because POINT is about experience, not about music.

In this respect, POINT helps to explain the underlying unease in Stanford. Most of the teachers gathered there were not entirely comfortable with a pedagogical focus on tools and skills- - how to hold the pencil, how to edit the sound-file, how to write invertible counterpoint. Many argued that the skills needed to change, to be reshaped to suit the current situation; but nearly all indicated that instruction in composition should also include something quite different—-"talent", "voice", "a 'way'.". But they were often at a loss to explain how to teach this. POINT helps us to understand that the two objectives are not, after all, sides of a single coin; they are wholly different species. In one case, teaching composition is a matter of production; it is goaldirected, skill-based, tool-specific. Composers learn how to make something. In the other, teaching composition is a matter of experience; it is open-ended, exploratory, experimental. Composers learn how to experience making something. No one denies the necessity for both; but only the latter leads to the esthetic.

\section{POINT and Education}

In a practical sense, POINT-like any research project-is concerned with the production of knowledge. New algorithms are written, new compositions come into being, new dialogues are had. New books, chapters, paragraphs are written. The knowledge enters the environment, and (one hopes) people use it. In this way POINT enriches a field of study, a domain of interactions.

But from Dewey's perspective an enriched domain is not in itself educational; all depends on what is done with it. Unless the interactions are such that the organismthe student-is enabled to grow further, in "an expanding world", they merely preserve established habits or, worse, impose additional restrictions on behaviour. In particular, an experience that leads to no questions, that simply provides the necessary answers, is not educational. One uses satellite navigation to obtain instructions for travel; these might be informative, but they are not educational. But when one uses a map, there arise possible questions about routes, terrain, and connections; in pursuing these, one obtains not just information but new insights, new possibilities. A cyclist setting out to explore an area wants a map, not a GPS device. The latter tells you "how to"; the former invites "what if". The latter is goal-directed, the former is exploratory.

For that reason, if POINT were only its "results", it itself would not be educational even if the results subsequently were used educationally. A participating composer who, through experiencing POINT, arrived at a definitive method for writing music and then used that method religiously for the indefinite future would, in fact, have 
been mis-educated by the experience. POINT is educational precisely to the extent that the circular process that animates it has no destination. The objective is to keep moving, to continue seeking an objective; the "results"- the compositions, the algorithms - are merely breadcrumbs dropped to mark the journey's path.

For the participating composers, then, POINT is educational not because they acquire insights into what they do but rather because they are led to speculations about what they might do. Self-knowledge is valuable primarily because it enables one to become other than what one is: it engenders growth. The experiments within POINT enter the field of past experiences and intermingle with their predecessors, establishing new relations between "parts of experience". To the extent that these relations are exploratory, in pursuit of an ever-receding theory, new experiences will be educational. And, not incidentally, these experiences will have a potential for producing artistic work, the basis for new esthetic experiences to be had by others. For the esthetic-like POINT, like education-is not realised in completed objects; it is found in experiences that fold back on themselves, that enrich the possibility of future esthetic experiences.

For the researcher, too, POINT's educational value does not lie in its accomplishments. Unexpected problems may have arisen and been overcome; new programming solutions may have been devised; new interfaces may have been built. These are well worth reporting and disseminating; they, too, enrich a field of study. But they are also best approached as an incomplete set of exploratory experiments: incomplete, first, because new composers will generate new problems, and there is no end to composers; but incomplete also because the set of relations between the solutions- the new "parts of experience" - and the greater environment raises new enquiries. It is not so much that "further research will follow" - that is merely a platitude-but that further research will be constantly transformed in an interactive cycle that is actually a (re-)application of the model applied in POINT itself. Education is viable to the extent that it reflexively and sustainably generates education; POINT is educative to the extent that it generates a further "POINT" in which it is itself a component.

And so also for the greater community of artists and researchers. POINT is educative to the extent that it invites continuation in new areas and new ways. We learn nothing if we take it as "finished". Future POINTs could simply move to new domains: one can easily imagine analogous projects for writers, for choreographers, for film-makers. But with such extensions POINT veers dangerously close to method, to doctrine; the experimental domain is enlarged, but the work is in some sense replicated. Rather, POINT - as an entity, not a collection of results - needs to enter the domain of discourse about artistic method, artistic research, artistic apprehension. There it can enter into new relations with other projects assembled, not quite arbitrarily, into a field for exploration, for experimentation.

A world of experience awaits. 


\section{Departure}

At the outset I spoke of "the harbour of my being". This was not just a poetic gesture: the metaphor is a true one. I am a harbour. My being-the water of the harbourinterpenetrates with the sea around it. In certain directions (from certain perspectives) the sea and the harbour cannot be clearly distinguished; still, there is another world, outside of the harboured self, with which I interpenetrate. Currents - tides — at times carry that other to me; at other times they carry me to it. There is undergoing and there is doing.

The harbour is, however bounded; reality has its limits. In both cases, the true boundary is the shore-the change from one state to another-and the world "beyond" is unknowable. The water cannot know the land: it only feels the land's constraint. It can lap gently or rage openly, but it gains access only by small, unnoticeable increments. And when access is gained, it takes the land into itself; water is a universal solvent. Thus I transcend myself, utterly unaware.

The other boundary - the vague, shifting edge between harbor and sea-is open to adventure. I can truly embark; the harbour can empty itself. To engage with the sea, I must abandon my habits: I must open myself to currents, forces, I cannot foresee. The adventure is founded on faith, an indefensible belief that understanding will result; but I commit myself — my self — thereby to being all at sea. There is no return except by fortune.

\section{References}

1. Applebaum M (2012) Existential crises in composition mentorship and the creation of creative agency. Contemp Music Rev 31(4):257-268

2. Bresnick M (2012) Thoughts about teaching composition, or self-portrait as Hamlet and Polonius and Whitman is also there. Contemp Music Rev 31(4):269-276

3. Brooks W (2007) Pragmatics of silence. In: Losseff N, Doctor J (eds) Silence, music, silent music. Ashgate Publishing, Aldershot, pp 97-126

4. Brooks W (2009) Sounds, gamuts, actions: Cage's pluralist universe. In: Essays on and around Freeman Etudes, Fontana Mix, Aria. Orpheus Institute, Ghent, pp 61-95

5. Brooks W (2012) In re: experimental music. Contemp Music Rev 31(1):37-62

6. Brooks W (2013) In re: Re. Unpublished paper, University of Illinois Composers' Forum

7. Brooks W (2014) In re: experimental analysis. Contemp Music Rev (in press)

8. Bruhn CE (2006) Ives's multiverse: the Concord Sonata as American cosmology. PhD thesis. University of New York, New York

9. Campion EJ (2012) Fitting Music Composition Studies for the 21st-Century American University. Contemp Music Rev 31(4):277-282

10. Clarkson A (2001) The intent of the musical moment. In: Bernstein DW, Hatch C (eds) Writings through John Cage's music, poetry, and art. University of Chicago Press, Chicago, pp 62-112

11. Contemporary Music Review (2012), vol 31(4)

12. Crooks EJ (2011) John Cage's entanglement with the ideas of Coomaraswamy. PhD thesis. University of York, York

13. Czernowin C (2012) Teaching that which is not yet there (Stanford version). Contemp Music Rev 31(4):283-289 
14. Dewey J (1916) Democracy and education. The Macmillan Company, New York

15. Dewey J (1922) Human nature and conduct. Henry Holt and Company, New York

16. Dewey J (1934) Art as experience. Minton, Balch and Company, New York

17. Dewey J (1938) Experience and education. The Macmillan Company, New York

18. Hiller LA, Isaacson LM (1959) Experimental music: composition with an electronic computer. McGraw-Hill Book Company, New York

19. Ives C (1962) Essays before a Sonata. In: Boatwright H (ed) Essays before a Sonata and other writings. Norton, New York

20. Ives C (1962) Some 'quarter-tone' impressions. In: Boatwright H (ed) Essays before a Sonata and other writings. Norton, New York

21. James W (1890) The principles of psychology. Henry Holt, New York

22. James W (1909) The meaning of truth: a sequel to 'pragmatism'. Longmans, Green, and Co, New York

23. Kostelanetz R (1970) The theatre of mixed means. Pitman, London

24. Lerdahl F (2012) On teaching composition. Contemp Music Rev 31(4):291-296

25. Lindroth S (2012) Teaching composition: artistic growth through confrontation, tact, sympathy, and honesty. Contemp Music Rev 31(4):297-304

26. Perry RS (1974) Charles Ives and the American mind. The Kent State University Press, Kent

27. Ran S (2012) On teaching composition. Contemp Music Rev 31(4):305-312

28. Retallack J (1994) Poethics of a complex realism. In: Perloff M, Junkerman C (eds) John Cage: composed in America. The University of Chicago Press, Chicago, pp 242-273

29. Reynolds R (2012) Thoughts on enabling creative capacity: provocation, invitation, resistance, and challenge. Contemp Music Rev 31(4):313-322

30. Ribe N, Steinle F (2002) Exploratory experimentation: Goethe, Land, and color theory. Phys Today 55(7):43-49

31. Schwab M (ed) (2013) Experimental systems: future knowledge in artistic research. Leuven University Press, Leuven

32. Steinle F (1997) Entering new fields: exploratory uses of experimentation. In: Philosophy of science. Biennial meetings of The Philosophy of Science Association, vol 64(2). University of Chicago Press, Chicago, pp S65-S74

33. Stroud SR (2011) John Dewey and the artful life: pragmatism, aesthetics, and morality. Pennsylvania State University Press, University Park

34. Ulman E (2012) An overview of the symposium. Contemp Music Rev 31(4):249-256 